\title{
ANÁLISE DA ESTRUTURA DE COMUNIDADES FITOPLANCTÔNICAS E DE ALGUNS FATORES ABIÓTICOS EM TRECHO DO RIO JACUÍ, RIO GRANDE DO SUL, BRASIL ${ }^{1}$
}

\author{
Zulanira Meyer Rosa ${ }^{2}$ \\ Lezilda Carvalho Torgan ${ }^{2}$ \\ Eduardo A. Lobo $^{3}$ \\ Lise Anne Wunderlich Herzog ${ }^{3}$
}

Recebido em 20-10-87. Aceito em 30-5-88.

\begin{abstract}
RESUMO - São apresentados os resultados do estudo do fitoplâncton e de algumas variáveis físicas e químicas da água em um trecho do Rio Jacuí, com base em amostragens realizadas em julho de 1986. As coletas foram efetuadas em três secções do rio, incluindo, além da área de influência direta de efluentes industriais, ricos em resíduo de carvão mineral, uma secção anterior e outra posterior às indústrias, visando a uma avaliação ambiental preliminar. Foram registrados 130 táxons de microalgas, sendo que seis constituem-se em primeira citação de ocorrência para o Estado. Destacaram-se as Bacillariophyta, as Chlorophyta e as Cyanophyta, quanto à densidade celular. Alterações na estrutura das comunidades fitoplanctônicas e em fatores abióticos do sistema, esperadas como decorrência da poluição industrial e orgânica local, não foram comprovadas, pois os valores de diversidade especifica do fitoplâncton, bem como de algumas variáveis físicas e químicas analisadas, não apresentaram diferenças significativas para as secções estudadas, devido, provavelmente, ao alto poder de diluição do Jacuí, em decorrência de sua vazão.
\end{abstract}

Palavras-chave: fitoplâncton, variáveis físicas e químicas, influência industrial de resíduos de carvão.

ABSTRACT - The structure of the phytoplankton communities on a stretch of the Jacuí River
and some chemical and physical variables of its aquatic environment were studied during July
1986. The sampling zone was divided into three sections: the area under direct influence of the
industrial wastes (mineral coal residues), and the areas upstream and downstream, trying to get

\footnotetext{
${ }^{1}$ Trabalho realizado no Museu de Ciências Naturais da Fundação Zoobotânica do Rio Grande do Sul, financiado pelo acordo FUNDATEC-ELETROSUL para a elabcração do RIMA da U.T. JACUÍ I

${ }^{2}$ Pesquisador da Fundação Zoobotânica do Rio Grande do Sul e bolsista do Conselho Nacional de Desenvolvimento Científico e Tecnológico - CNPq. Av. Salvador França, 1427 - 90610 - Porto Alegre-RS

${ }^{3}$ Bolsista do Museu de Ciências Naturais da Fundação Zoobotânica do Rio Grande do Sul, Caixa Postal 1188 - 90610 - Porto Alegre-RS
} 
a preliminary environment evaluation. According to the local organic and industrial pollution, changes on the structure of the communities and abiotic factors were expected, but they were not confirmed since the specific diversity of the communities, as well as some chemical and physical variables analysed did not show significant differences among the sections studied, probably due to the great discharge of the river and, consequently, high dilution power. Considering the cells density, Bacillariophyta, Chlorophyta and Cyanophyta were the representative groups. One hundred and thirty taxa were identified, six of them being new records for the State.

Key words: phytoplankton communities structure, chemical and physical variables, coal wastes influence.

\section{Introdução}

A estrutura de comunidades de algas, determinada através de indicadores tais como composição específica, densidade celular, riqueza de espécies e uniformidade específica, pode ser utilizada como base para avaliação da qulidade de um sistema aquático, podendo a medida da diversidade específica constituir-se em um bom índice de comparação das condições ambientais.

Com base nesse conhecimento, foi efetuado o estudo de comunidades fitoplanctônicas, associado a medições de alguns fatores físicos e químicos em um trecho do Rio Jacuí, com o objetivo de efetuar, além do inventário de táxons ocorrentes, uma avaliação preliminar da qualidade daquele ambiente.

O Jacuí é um dos maiores rios que percorrem a região centro-leste do Estado do Rio Grande do Sul. Possui cerca de $720 \mathrm{~km}$ de extensão e recebe, ao longo de seu percurso, a contribuição de vários arroios e rios. É um dos principais tributários do Guaíba, manancial que abastece a população da cidade de Porto Alegre. $\mathrm{O}$ conhecimento da flórula ficológica e de condições físicas e químicas das águas do Jacuí limita-se a dados publicados pelo Departamento Municipal de Águas e Esgotos de Porto Alegre (Porto Alegre, 1974; 1981). Nesses relatórios, é apresentada uma listagem de diatomáceas a nível específico, sendo os demais grupos identificados a nível genérico; são também incluídos alguns dados de densidade média de diferentes grupos fitoplanctônicos, bem como registro de um número considerável de variáveis abióticas.

O presente trabalho apresenta informações referentes à composição de comunidades fitoplanctônicas em um segmento do Rio Jacuí, sua densidade, diversidade específica, assim como riqueza e uniformidade de espécies, relacionando também algumas variáveis físicas e químicas e comparando os valores obtidos com os já registrados para a área, na tentativa de avaliar as condições do biótopo no período de amostragem.

\section{Material e métodos}

Foram realizadas amostragens em três secções do Rio Jacuí em julho de 1986. As secções amostradas (Fig. 1) foram localizadas uma em trecho entre as cidades de São Jerônimo e Charqueadas (secção 3), outra junto às Indústrias Aços Finos 
Piratini e Termelétrica Charqueadas (seç̧ão 4) e a última imediatamente após a área industrial, junto ao Município de Guaíba (secção 5). Os pontos de amostragem foram os seguintes: ponto 3a, junto à praia de São Jerônimo, próximo à junção dos rios Jacuí e Taquari; ponto 3c, ponto médio entre o encontro dos rios e oeste da Ilha da Paciência; ponto 3e, a oeste da Ilha da Paciência; ponto 4a, cerca de $20 \mathrm{~m}$ abaixo da Termelétrica de Charqueadas, a oeste da Ilha das Cabras; ponto 4c, cerca de $20 \mathrm{~m}$ abaixo da Aços Finos Piratini; ponto 4e, em frente à Penitenciária Estadual do Jacuí; ponto 5a, cerca de $20 \mathrm{~m}$ abaixo da desembocadura do Arroio dos Ratos; ponto 5c, entre a desembocadura do Arroio dos Ratos e leste da Ilha dos Dorneles; e ponto 5e, a leste da Ilha dos Dorneles.

As amostras, num total de 18 , foram coletadas com frasco e rede de malha de $36 \mu \mathrm{m}$, próximo à superfície da água, entre o canal do rio e sua margem direita, sendo fixadas com solução de lugol e formalina, respectivamente.

Para análise quantitativa do fitoplâncton, foram estudadas somente as amostras não seletivas, sendo aplicado o método de Utermöhl (1958) e utilizado microscópio invertido WILD M40.

A análise taxonômica foi efetuada em microscópio de pesquisa Leitz, mod. Dialux, tendo sido preparadas lâminas permanentes para o estudo das Bacillariophyta, através de oxidação com ácido nítrico. A classificação apresentada segue o sistema de Round (1973).

As amostras foram tombadas no Herbário Prof. Dr. Alarich R.H. Schultz (HAS) do Museu de Ciências Naturais da Fundação Zoobotânica do Rio Grande do Sul, sob os números HAS16583 a HAS16601.

Para determinação da estrutura das comunidades de algas, foram considerados, entre as diatomáceas, somente os organismos com cromoplastos, tendo sido utilizados os seguintes indicadores: densidade celular expressa em número de células por ml; diversidade específica utilizando o índice de Shannon \& Weaver (1949), com adaptações baseadas em Pielou (1975); e espécies dominantes e abundantes, segundo o critério de Lobo \& Leighton (1986).

Do total de variáveis físicas e químicas analisadas, a condutividade, a temperatura, o oxigênio dissolvido, o pH e a transparência foram medidos in situ, utilizando, respectivamente, condutivímetro salinômetro YS0 mod. 33, oxímetro YS1 mod. 57, medidor WTW mod. D8120 Weimen e disco de Secchi. Sulfetos e fosfatos foram medidos pelo método colorimétrico; turbidez pelo método meselométrico; DQO por digestão com dicromato de potássio; dureza pelo método titulométrico; ferro por espectrofotometria de absorção atômica, tendo sido estas análises efetuadas por técnicos do Instituto de Pesquisas Hidráulicas da Universidade Federal do Rio Grande do Sul. Os nitratos, nitritos, NMP de coliformes fecais e totais foram medidos por técnicos do Departamento Municipal de Águas e Esgotos de Porto Alegre, seguindo a metodologia transcrita em Porto Alegre (s/data). As variáveis medidas foram comparadas com os valores registrados para a área de estudo (Porto Alegre, 1974; 1981). 
Foi utilizada a prova de Kruskal-Wallis (Siegel, 1975) para comparar as diversidades específicas e as variáveis físicas e químicas medidas in situ entre as diferentes secções do rio. Trabalhou-se com intervalo de confiança de $\mathbf{9 0 \%}$.

\section{Resultados}

A análise qualitativa do fitoplâncton do trecho do Rio Jacuí compreendido entre a cidade de São Jerônimo e região norte do Município de Guaíba resultou na identificação de 130 táxons, pertencentes às divisões Cyanophyta, Chrysophyta, Bacillariophyta, Chlorophyta, Euglenophyta, Dinophyta e Cryptophyta. A composição florística, inventariada no período de estudo e analisada com base na amostragem coletada com frasco e rede, encontra-se relacionada a seguir.

Divisão CYANOPHYTA

Classe Cyanophyceae

Ordem Chroococcales: Merismopedia sp. e Microcystis aeruginosa Kützing

Ordem Oscillatoriales: Anabaena circinalis Rabenhorst ex Bornet \& Flahault; $A$. constricta Hassal ex Bornet \& Flahault; A. solitaria Klebahn; Lyngbya sp.; Oscillatoria formosa Bory ex Gomont; $O$. irrigua Kützing ex Gomont; $O$. limnetica Lemmermann; e Oscillatoria sp.

Divisão CHRYSOPHYTA

Classe Chrysophyceae

Ordem Chrysomonadales: Dinobryon sertularia Ehrenberg; Dinobryon sp.; Mallamonas sp.; Synura uvella Ehrenberg; e Synura sp.

Divisão BACILLARIOPHYTA

Classe Centrobacillariophyceae

Ordem Centrales: Aulacosira ambigua (Grunow) Simonsen; A. distans (Ehrenberg) Simonsen; $A$. granulata (Ehrenberg) Simonsen; $A$. granulata (Ehrenberg) Simonsen var. angustissima (O. Müller) Simonsen; Aulacosira sp.; Cyclotella sp.; Hydrosera whampoensis (Schwartz) Deby; Pleurosira laevis (Ehrenberg) Compère; Paralia sulcata (Ehrenberg) P.T. Cleve; e Terpsinoe musica Ehrenberg.

Classe Pennatibacillariophyceae

Ordem Pennales: Achnanthes exigua Grunow; A. exigua Grunow var. constricta (Grunow) Hustedt; $A$. inflata (Kützing) Grunow; $A$. microcephala (Kützing ) Grunow; Achnanthes sp.; Amphipleura sp.; Amphora sp.; Cymbella minuta Hilse ex Rabenhorst; Cymbella sp.; Diploneis subovalis P.T. Cleve; Eunotia camelus Ehrenberg; E. didyma Hustedt ex Zimmermann var. pseudogibbosa Torgan; E. lunaris (Ehrenberg) Grunow; E. sudetica O. Müller; E. pectinalis (O. Müller) Rabenhorst; E. pectinalis (O. Müller) Rabenhorst var. ventralis (Ehrenberg) Hustedt; E. rabenhorstii Cleve \& Grunow var. monodon P.T. Cleve \& Grunow; Eunotia sp.; Frustulia rhomboides (Ehrenberg) De Toni; F. rhomboides (Ehrenberg) De Toni var. ca- 
pitata (A. Mayer) Patrick; Gomphonema sp.; Gyrosigma sp.; Navicula contenta Grunow; $N$. cryptocephala Kützing var. veneta (Kützing) Grunow; N. mutica Kützing; N. pupula Kützing; Navicula sp.; Nitzschia amphibia Grunow; N. frustulum (Kützing) Rabenhorst; $N$. palea (Kützing) W. Smith; N. paleaceae Grunow; Nitzschia sp.; Neidium iridis (Ehrenberg) P.T. Cleve; Pinnularia borealis Ehrenberg; $P$. microstauron (Ehrenberg) P.T. Cleve; Pinnularia sp.; Surirella delicatissima Lewis; Surirella sp.; Synedra acus Kützing; S. ulna (Nitzsch) Ehrenberg; S. rumpens Kützing; Stauroneis anceps Ehrenberg var. anceps f. gracilis Rabenhorst; e S. phoenicenteron Ehrenberg.

\section{Divisão CHLOROPHYTA}

Classe Chlorophyceae

Ordem Volvocales: Eudorina elegans Ehrenberg; Eudorina sp.; Pandorina morum (Müller) Bory; Pandorina sp.; e Volvulina sp.

Ordem Chlorococcales: Ankistrodesmus gracilis (Reinsch) Korsikov; $A$. spiralis (Turner) Lemmermann; Chlorella sp.; Coelastrum sp.; Crucigenia tetrapedia (Kirchner) West \& West; Dictyosphaerium pulchellum Wood; Dictyosphaerium sp.; Monoraphidium contortum Komárkova-Legnerová; Monoraphidium sp.; Pediastrum duplex Meyen; P. simplex Meyen; Scenedesmus armatus (Chodat) G.M. Smith; e Scenedesmus sp.

Classe Oedogoniophyceae

Ordem Oedogoniales: Oedogonium sp.

Ordem Gonatozygales: Gonatozygon monotaenium De Bary

Ordem Mesotaeniales: Netrium digitus (Ehrenberg) Itzigson \& Rothe Ordem Desmidiales: Bambusina brebissonii Kützing; e Closterium acerosum (Schrank) Ehrenberg var.?; C. ehrenbergii Meneghini; C. moniliferum (Bory) Ehrenberg; $C$. setaceum Ehrenberg; Closterium sp.; Cosmarium binum Nordstedt; $C$. botrytis (Meneghini) Ralfs; $C$. connatum (Brébisson) Ralfs; $C$. lagoense Nordstedt var. amoebum Förster \& Eckert; $C$. ornatum Ralfs var.?; Cosmarium sp.; Desmidium swartzii (C. Agardh) C. Agardh ex Ralfs var. amblyodon (Itzigson) Rabenhorst; D. swartzii (C. Agardh) C. Agardh ex Ralfs var.?; Desmidium sp.; Euastrum gemmatum Brébisson var.?; E. spinulosum Delponte var.?; Euastrum sp.; Hyalotheca dissiliens (Smith) Brébisson; Micrasterias truncata (Corda) Brébisson var. pusilla G.S. West; Pleurotaenium ehrenbergii (Brébisson) De Bary; Pleurotaenium sp.; Staurastrum bifidum (Ehrenberg) Brébisson; S. cuspidatum (Brébisson) Ralfs var.?; $S$. dejectum Brébisson; $S$. hantzschii Reinsch var. congrum (Raciborski) West $\&$ West; $S$. margaritaceum (Ehrenberg) Ralfs; $S$. rotula Nordstedt; $S$. setigerum Cleve var.?; Staurastrum sp.; e Xanthidium sp.

Ordem Zygnemales: Mougeotia sp.

Divisão EUGLENOPHYTA

Classe Euglenophyceae 
Ordem Euglenales: Euglena acus Ehrenberg; Euglena sp.; Phacus longicauda (Ehrenberg) Dujardin; Phacus sp.; Trachelomonas volvocina Deflandre; T. volvocinopsis Swirenko; e Trachelomonas sp.

\section{Divisão DINOPHYTA \\ Classe Dinophyceae}

Ordem Peridiniales: Peridinium gatunense Nygaard.

\section{Divisão CRYPTOPHYTA}

Classe Cryptophyceae

\section{Ordem Cryptomonadales: Cryptomonas sp.}

Dos táxons identificados, seis constituem-se em primeiros registros de ocorrência para o Estado do Rio Grande do Sul: Oscillatoria formosa Bory ex Gomont, O. limnetica Lemmermann, Cosmarium binum Nordstedt, $C$. botrytis (Meneghini) Ralfs, Staurastrum bifidum (Ehrenberg) Brébisson e $S$. hantzschii Reinsch var. congrum (Raciborski) West \& West.

Das espécies de diatomáceas registradas sempre sem cromoplastos, devem ser destacadas Terpsinoe musica Ehrenberg, Pleurosira laevis (Ehrenberg) Compère, Paralia sulcata (Ehrenberg) P.T. Cleve e Coscinodiscus sp. como elementos provavelmente alóctones ao ambiente. A ocorrência acidental dessas espécies no plâncton pode ter sido determinada pelo aporte de material de fundo proveniente de depósitos sedimentares da região.

Com referência à densidade do fitoplâncton, as Bacillariophyta (diatomáceas) foram o grupo mais representativo, seguido das Chlorophyta nas secções 4 e 5 e das Cyanophyta na 3. Os demais grupos apresentaram baixa densidade celular, inferior a $7 \%$ da densidade total (Fig. 2).

A densidade total oscilou entre o máximo de $17 \times 10^{2}$ cél. $/ \mathrm{ml}$ e o mínimo de $0,5 \times 10^{2}$ cél./ml (Fig. 3), observando-se uma tendência à redução nos valores da secção 3 para a 5 . Não foi constatada dominância de qualquer táxon, segundo o critério adotado, estando as espécies abundantes registradas na Tabela 1 .

Quanto à uniformidade de espécies, a tendência foi oposta à da densidade, havendo um aumento gradual da secção 3 para a 5 (Fig. 4).

Com relação à diversidade específica (Fig. 5), observou-se como valor mínimo 2,20nat/cél. na secção 3 e como máximo 2,77nat/cél. na secção 4, não havendo diferença significativa entre as médias obtidas $(P<0,10)$.

Os fatores físicos e químicos analisados apresentaram as seguintes variações: temperatura entre 15 e $16^{\circ} \mathrm{C} ; \mathrm{pH}$ entre 5,8 e 7,5, sendo o valor máximo encontrado para a secção 4 e o mínimo para a 5 ; transparência entre 25 e $30 \mathrm{~cm}$; oxigênio dissolvido entre $6,8 \mathrm{mg} / 1$ para a seç̧ão 5 e $8,2 \mathrm{mg} / 1$ para as 3 e 4 ; e condutividade de 35 a $40 \mu$ mhos. Considerando as médias dessas variáveis, constatou-se que não houve diferenças significativas $(\mathrm{P}<0,10)$ entre as três secções amostradas (Fig. 6).

Os resultados dos demais fatores analisados encontram-se na Tabela 2. 


\section{Discussão}

A hipótese de que pudesse haver diferenças significativas para fatores físicos, químicos e biológicos da água entre as secções estudadas baseou-se nas características peculiares a cada seç̧ão, oriundas da introdução de despejos orgânicos, industriais e de mineração naquele ambiente.

A quantidade considerável de sólidos em suspensão na água, evidenciados por ocasião da coleta e que se constituíam basicamente em cinza de carvão mineral, proporcionaria, teoricamente, redução nos valores de $\mathrm{pH}$, aumento da condutividade elétrica e também maiores concentrações de ferro e sulfatos, como resultado da oxidação da pirita (FeS) existente na cinza do carvão, devendo esses efeitos fazerem-se presentes, ainda, em águas usadas no processo de mineração que chegam ao rio através do Arroio dos Ratos, no início da secção 5. A transparência também deveria apresentar valores superiores nesses ambientes, constatação feita para ambientes lênticos da região (Rosa et al., 1987). Esses fatores ambientais, entre outros, além de efeitos resultantes da introdução de resíduos orgânicos junto à cidade de São Jerônimo, deveriam interferir na composição e na estrutura das comunidades vivas daquele ambiente aquático.

A constância, não esperada, encontrada para a diversidade específica poderia ser explicada com base nos dados de uniformidade de espécies e densidade celular, já que os valores obtidos para riqueza de espécies, se comparados entre as três secções do rio (Fig. 7), também não apresentaram diferenças significativas. Como pode ser observado na Fig. 8, enquanto a densidade mostra uma tendência à redução da secção 3 para a 5 , a distribuição entre as espécies aumentou no sentido inverso. A interação entre eșsas duas variáveis (densidade e uniformidade) pode ter sido um dos fatores determinantes da estabilidade da diversidade específica. Essa estabilidade poderia, ainda, ser atribuída ao fato de não terem sido encontradas diferenças significativas para os fatores ambientais medidos por ocasião da coleta (oxigênio dissolvido, temperatura, $\mathrm{pH}$, transparência e condutividade). Isto não implica, entretanto, o fato de que tais fatores pudessem constituir-se nos responsáveis pela constância observada, tendo, provavelmente, os mesmos contribuído para mantê-la.

Nos valores obtidos para densidade (Fig. 3), pode ser observado que, além da tendência de redução da secção 3 para a 5, os valores mínimos foram sempre coincidentes com as porções iniciais dos segmentos estudados, o que pode estar relacionado com o fato de os mesmos constituírem-se em áreas de impacto pelo aporte de material poluidor: por poluentes orgânicos introduzidos por esgotos da cidade de São Jerônimo (porção inicial da secção 3); resíduos industriais ricos em carvão mineral introduzidos pelas indústrias locais (porção inicial da secção 4); resíduos orgânicos e de mineração, estes últimos oriundos da pré-lavagem do carvão na área de mineração, transportados ao rio através da desembocadura do $\mathrm{Ar}$ roio dos Ratos (porção inicial da secção 5). As recuperações do fitoplâncton, em 
densidade, que se sucederam ao longo das secções possivelmente são decorrentes do alto poder diluidor do Rio Jacuí (vazão média de $714 \mathrm{~m}^{3} / \mathrm{s}$ ). Os valores máximos de densidade obtidos junto à secção 3 , por conseguinte, podem ser explicados pela contribuição das águas do Rio Taquari, que, segundo Porto Alegre (1974), apresentaria número mais elevado de organismos, se comparado ao Rio Jacuí.

$\mathrm{O}$ indicador diversidade específica, que se mostrou eficiente para apontar alterações na estrutura de comunidades de ambientes lênticos do Sistema Jacuí (Rosa et al., 1987), que sofrem influência direta da introdução de resíduo de carvão mineral, não apresentou aplicabilidade para a porção lótica do sistema. As diferenças não significativas encontradas para diversidade sugerem que esse indicador não se constitui em elemento aplicável à avaliação de ambientes lóticos, especialmente daqueles com alto poder diluidor, sendo o impacto localizado dissipado rapidamente e não havendo, portanto, tempo para modificações na estrutura das comunidades de algas que pudessem ser detectadas através do índice de diversidade, por exemplo.

Com relação ainda a fatores biológicos, merece referência a constatação, entre as espécies abundantes (Tab. 1), da ocorrência de Aulacosira granulata (Ehrenberg) Simonsen e Nitzschia palea (Kützing) W. Smith, organismos que, segundo Lowe (1974), constituem-se em espécies alcalófilas, o que poderia indicar certa estabilidade para o pH, dentro de níveis não-ácidos; ambas as espécies são citadas na literatura para ambientes eutróficos, sendo a última referida como tolerante a amplas condições ecológicas e citada por Palmer (1959) como indicadora de poluição orgânica e da presença de resíduos industriais de cobre, ácido sulfídrico e cromo.

Para fatores físicos e químicos, comparando os valores obtidos para a secção $4 \mathrm{com}$ as médias registradas para o mesmo local pelo Departamento Municipal de Águas e Esgotos de Porto Alegre - DMAE, referentes a medições efetuadas nos anos de 1971 e 1973 a 1980, pode-se observar que, para transparência, dureza, DQO e nitrito, foram obtidos, no presente trabalho, valores inferiores às médias, mas superiores aos valores mínimos registrados. Para o $\mathrm{pH}$, foram obtidos valores próximos às médias e para turbidez, oxigênio dissolvido, ferro, DBO, nitrato e número mais provável de coliformes fecais e totais, valores superiores às médias, mas inferiores aos máximos registrados para o local. Os teores de sulfato, entretanto, mostraram-se acima da média indicada para a estação considerada pelo DMAE, acima dos valores máximos, como também foram superiores às médias indicadas para os diferentes trechos estudados ao longo do Rio Jacuí.

Se comparados os valores médios de temperatura, $\mathrm{pH}$ e condutividade (Fig. 6), podem-se constatar valores superiores desses parâmetros na secção 4 , relativamente às demais secções; a transparência teve seu valor médio superior na secção 5 e o oxigênio valor médio inferior também para aquela secção, assim como os menores valores para $\mathrm{pH}$ e transparência (ponto 5a). Estas seriam diferenças esperadas, de acordo com a hipótese proposta; entretanto, com o teste de estatística 
não-paramétrica aplicado, não foram encontradas diferenças significativas entre as variáveis analisadas.

Considerando que alguns fatores ambientais medidos mostraram-se acima dos valores médios e até máximos registrados para a área e que este fato esteve associado à abundância de espécies indicadoras de poluição, acredita-se que a área se encontre em processo de contaminação química e orgânica, cuja detecção não se faça sentir com a utilização dos indicadores utilizados, pelo poder de diluição do sistema, como também pelo fato de os processos químicos e biológicos envolvidos não apresentarem resposta imediata às modificações ambientais introduzidas naquele ambiente. Cabe destacar que os resultados são de caráter preliminar, sendo convenientes estudos intensivos, ao longo do tempo, incluindo estudos de comunidades perifíticas e bentônicas que, certamente, constituir-se-ão em elementos mais eficientes, por permanecerem, por mais tempo, sujeitos às condições locais, possibilitando uma efetiva avaliação biológica das condições de trofia e contaminação ambiental.

\section{Agradecimentos}

À desenhista Rejane Rosa, pela cobertura a nanquim das ilustrações, e à bióloga Olda Delani e à funcionária do Departamento Municipal de Águas e Esgotos de Porto Alegre, Isabel Cristina Junqueira, pela colaboração prestada.

\section{Referências bibliográficas}

LOBO, E.A. \& LEIGHTON, G. 1986. Estructuras comunitarias de las Fitocenosis planctónicas de los sistemas de desembocadura de rios y esteros de la Zona Central de Chile. Rev. Biol. Mar., Valparaíso, Chile, 22(1): 1-29.

LOWE, R.L. 1974. Environmental requirements and polution tolerance of freshwater diatoms. Cincinnati, Ohio, Environmental Protection Agency, 334 pp. (Environmental Moniţoring Series).

PALMER, M.C. 1959. Algae in water supplies. Washington, U.S. Department of Health, Education, and Welfare, Public. Heatter Service, VI, 88 pp., 6 pl., 55 fig.

PIELOU, E.C. 1975. Ecological diversity. New York, John Wiley \& Sons, Inc., 165 pp.

PORTO ALEGRE. Departamento Municipal de Águas e Esgotos. 1974. As águas do Rio Jacui. Porto Alegre. 105 pp. (DMAE 14).

.1981. As águas do Rio Jacuí. Porto Alegre. vol. 2, 65 pp. (DMAE 36).

.[s.d]. Manual para técnicos encarregados de plantas de tratamento de água. Porto Alegre, $261 \mathrm{pp}$.

ROSA, Z.M. et alii. 1987. Ficoflora de ambientes lênticos - estudo preliminar da região de Charqueadas, Rio Grande do Sul, Brasil, com vistas à avaliação ambiental. Acta bot. bras. 1(2): 165-88.

ROUND, F.E. 1973. The Biology of the Algae. 2. ed. London, Edward Arnold, 277 pp.

SHANNON, C.E. \& WEAVER, W. 1949. The mathematical theory of communication. In: Ecologia. (Odum, E.P., 1972). 3. ed. México, Nueva Editorial Interamericana, 639 pp. 
SIEGEL, S. 1975. Estatística não-paramétrica para as ciências do comportamento. McGrawHill, Inc., $350 \mathrm{pp}$.

UTHERMÖHL, H. 1958. Perfeccionamento del método quantitativo de fitoplancton. Associación Internacional de Limnologia Teórica y Aplicada. Comité de Métodos Limnológicos, 50 pp. (comunicación 9). 


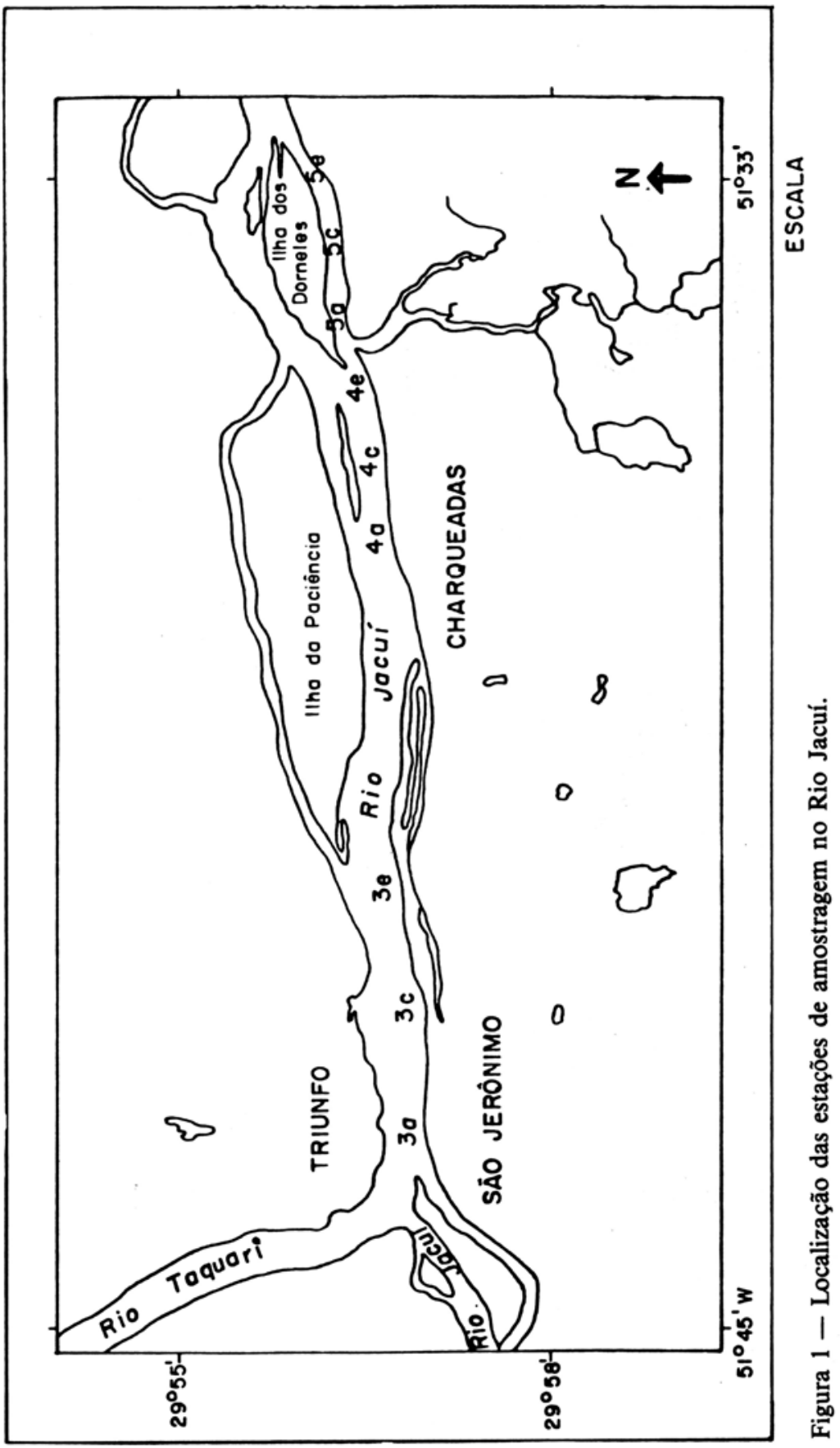



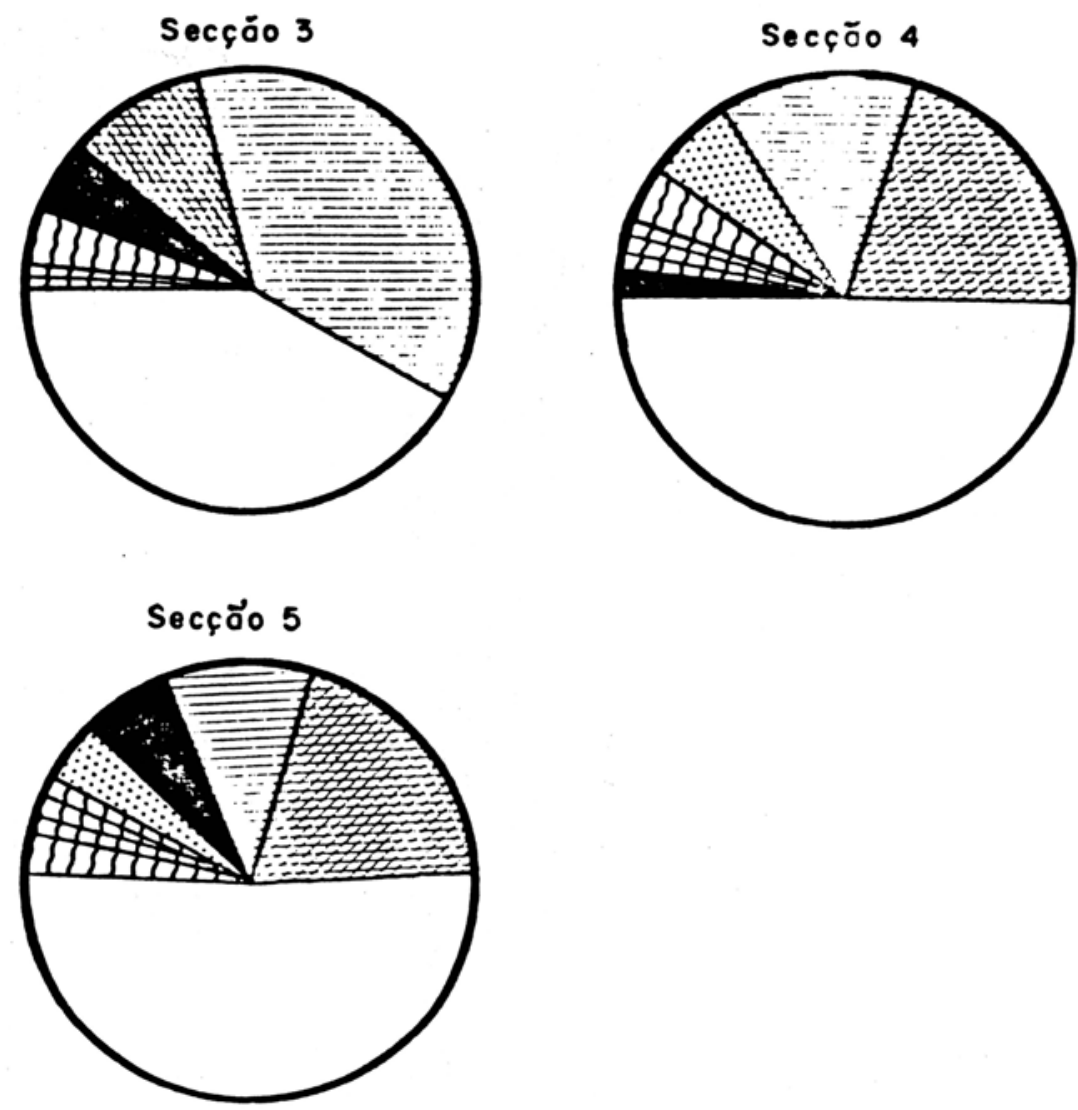

$\square$ Bocilloriophyto

Cryptophyto

Eyanophyto

团 Euglenophyto

彗 Chlorophyto

[D] Outros grupos

D Chrysophyto

Figura 2 - Percentagens de abundância de grupos fitoplanctônicos nas secções 3, 4 e 5 do Rio Jacuí (amostragens realizadas em julho de 1986). 


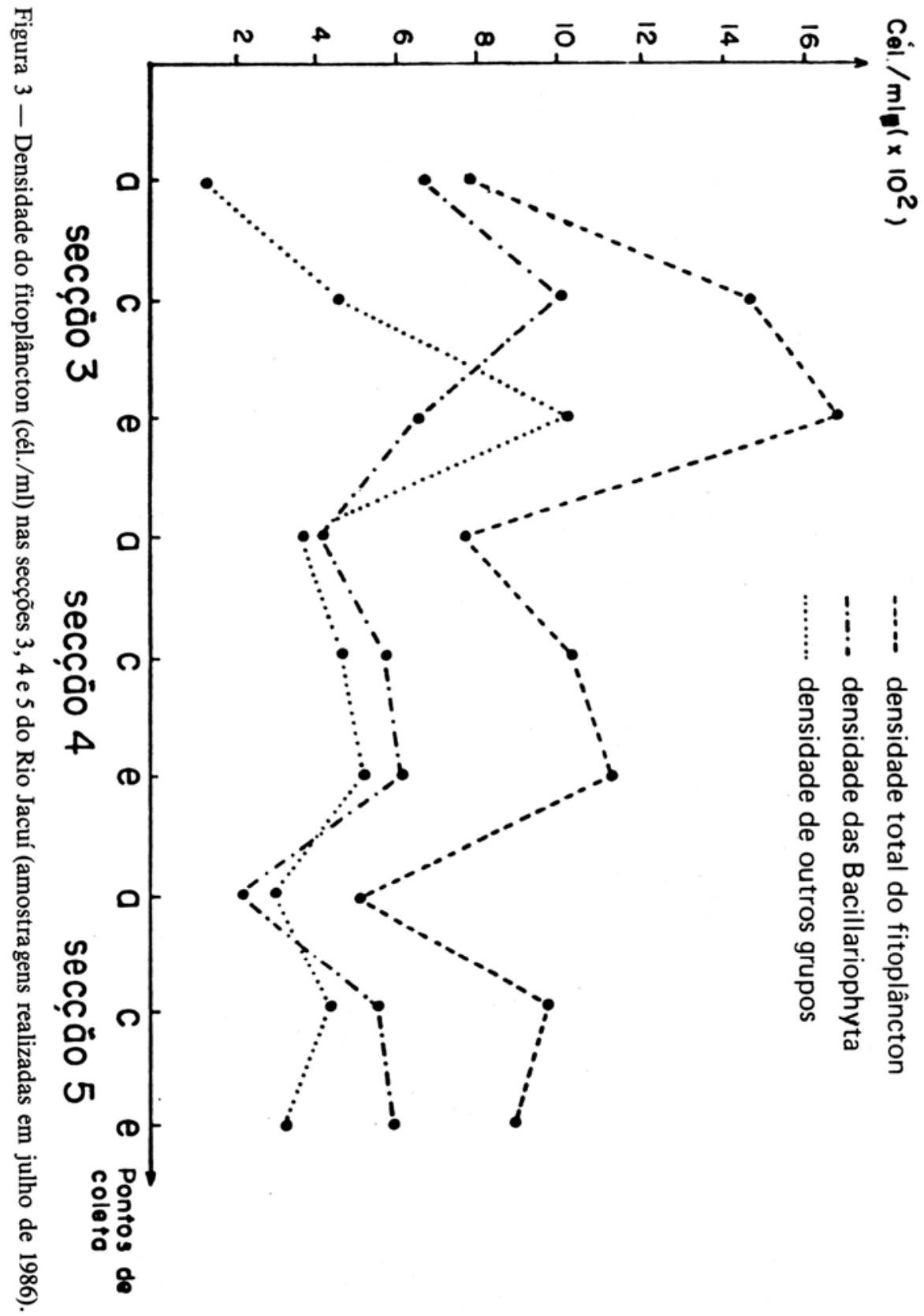




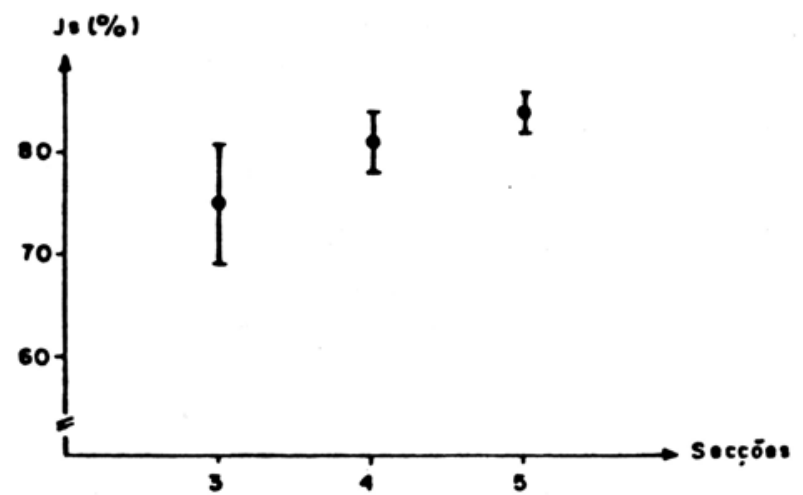

Figura 4 - Médias e desvios-padrão da uniformidade de espécies (Js) nas secções 3, 4 e 5 do Rio Jacuí (amostragens realizadas em julho de 1986).

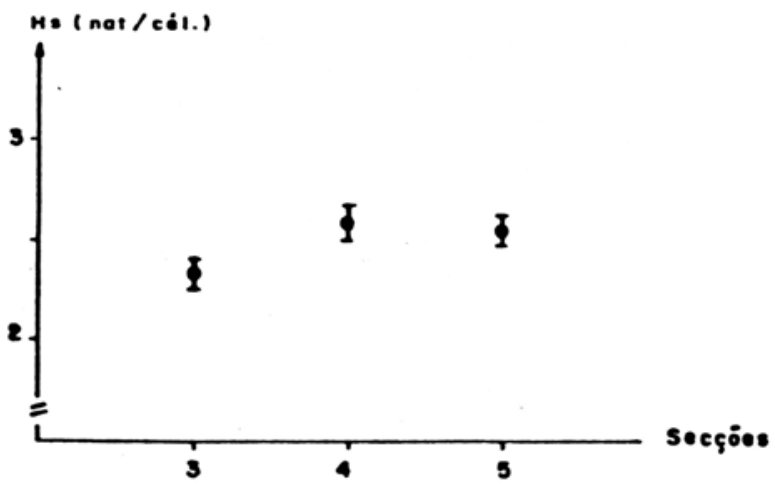

Figura 5 - Médias e desvios-padrão da diversidade específica (Hs) nas secções 3, 4 e 5 do Rio Jacuí (amostragens realizadas em julho de 1986). 

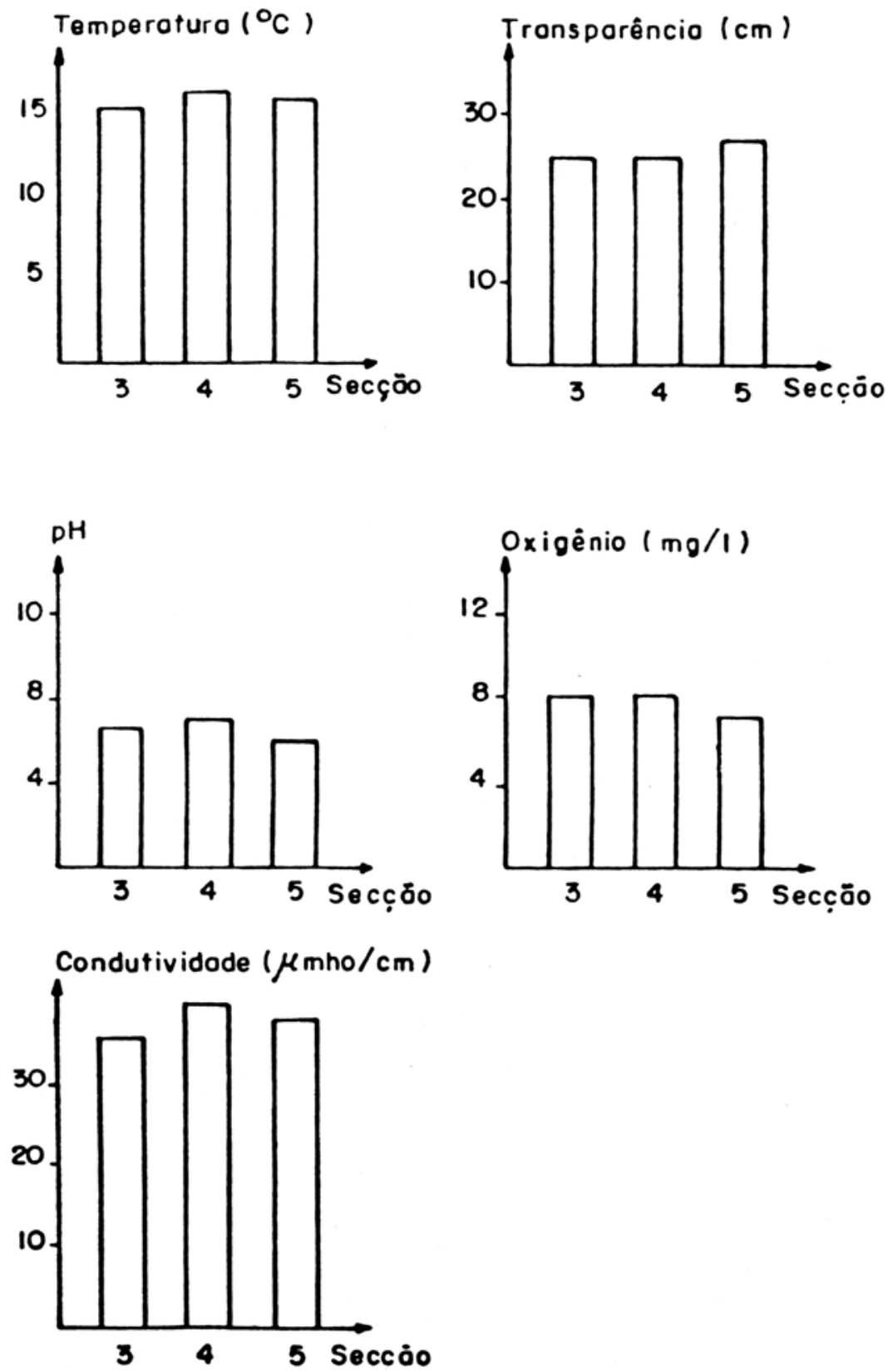

Figura 6 -Médias de variáveis físicas e químicas nas secções 3, 4 e 5 do Rio Jacuí (amostragens realizadas em julho de 1986). 


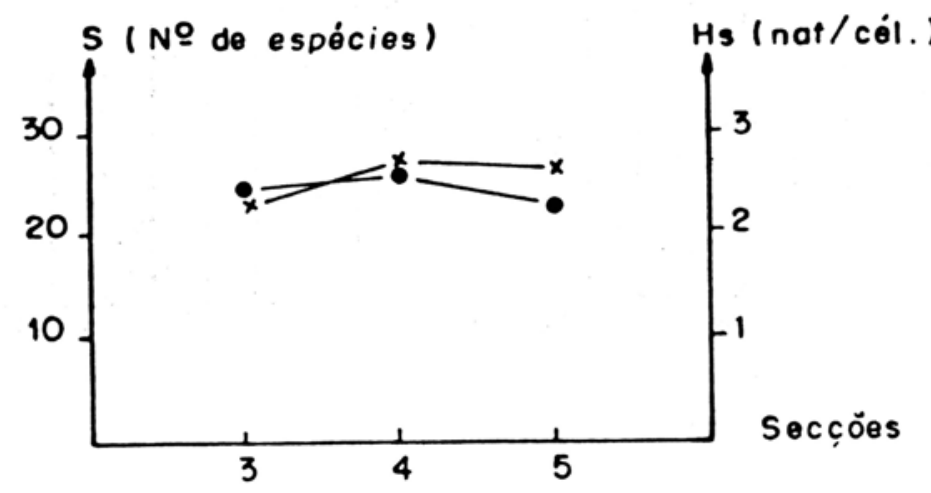

- Riquezo de espécies (S)

$\times$ Diversidode específica ( $\mathrm{Hs}$ )

Figura 7 - Médias da riqueza de espécies (S) e diversidade específica (Hs) nas secções 3, 4 e 5 do Rio Jacuí (amostragem realizada em julho de 1986).

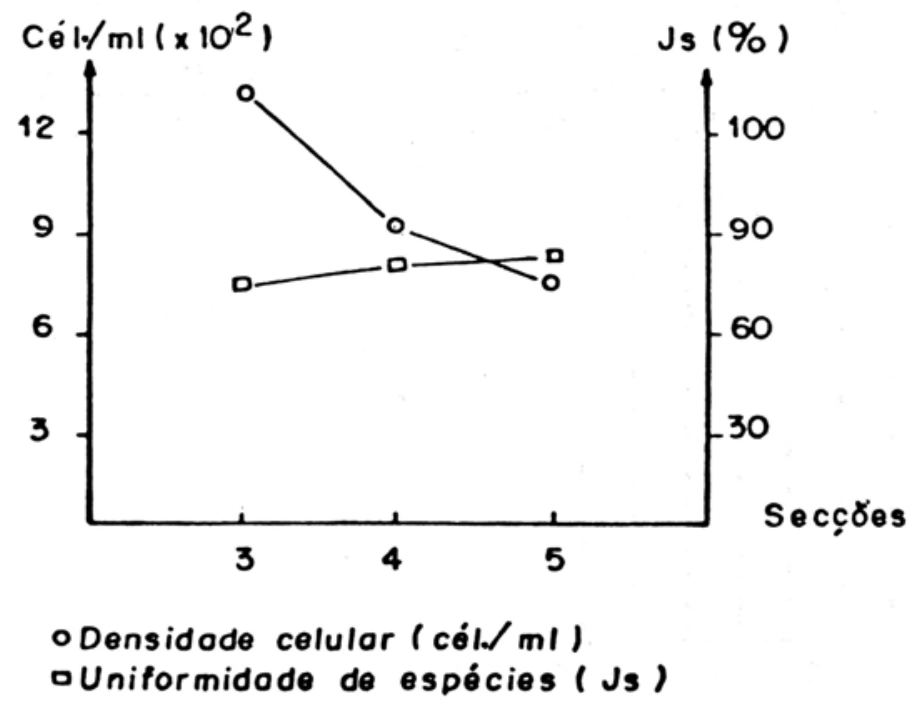

Figura 8 - Médias da densidade celular (cél./ml) e uniformidade de espécies (Js) nas secções 3, 4 e 5 do Rio Jacuí (amostragens realizadas em julho de 1986). 